\title{
Communicatietraining in het nieuwe curriculum te Nijmegen: van vraagverheldering naar verkenning van het referentiekader
}

\author{
E.M. van Weel-Baumgarten, K.P.M. van Spaendonck
}

\section{Samenvatting}

In het neuwe curriculum van de geneshundeopleiding te Nimegen word een nieuwe benadering toegepast bij het trainen van communicatevadigheden. Waggenheldering wordt eerst apart geofend, warna de andere onderdelen van het consult geleidelik worden toegevoegd en geintegreerd geoefend De vragverheldering is uitgebreid tot een verkenning van het referentiekader van de patent an de hand van het biopsychosociale tiektemodel. Dese aanpak bied structur aan studenten, observatoren en docenten, makk het stidenten makkeliker de patent persoonlike vragen te stehen en levert relevante informate op. Na uitleg en zelfstideopdrachten ofenen studenten ondering. Daama ofenen zij met simulatiepatenten en krigen van hen persoonlijk feedback zowel studenten als docenten bliken zeer tevreden te zin over dese aanpak. Het is de bedoeling dat dese methode ook toegepast $z a l$ worden bij andere vormen van medische consulten tidens de opleiding.

\section{Summary}

The recently restuctured undergraduate medical curriculum of Nimegen Unversity inchdes a new approach to communication skills traing. Medical interview skils are trained in three stages. Training starts by exploring the complaints presented by the patient then the specific history is added and finaly a complete history is practised. The exploration of the patient's complaints has been extended to an exploration of the patient's frame of reference using the biopsychosocial disease model. In additon to offering students, observers, and teachers a structured approach to the medical interview, this model makes it easier for stidents to overcome their embarrasment about asking patients rather delicate personal questions and it yields relevant data. First, the approach is explained to students, then they are given self study assignments and practise with one another. Subsequently stidents interview standardised patients and receive feedback from these patients. Both students and teachers express high satisfaction with this new approach, which is also to be introduced in other forms of medical interview training. (Communication training in the new Mimegen curriculum: from clarification of queston to frame of reference. Wan Weel Baumgarten EM, Van Spandonck KPM. Dutch Joumal of Medical Education 20o0; $19(1) \cdot 16-20)$

\section{Inleiding}

In Nijmegen is in 1995 een start gemaakt met een nieuw curriculum voor de studie medische wetenschappen. In dit curriculum is aan het begin van het derde studiejaar het eerste vaardigheidsblok gepland, dat vier weken duurt. In dit blok is een belangrijke plaats ingeruimd voor een communicatietraining. Bij deze training wordt de opbouw van het consult in vraagverheldering, speciële en tractusanamnese gevolgd. In het verleden werd de vraagverheldering vaak het kind van de rekening. Studenten werd aangeraden met open vragen patiënten aan te moedigen hun "verhaal" te vertellen vanuit de veronderstelling dat het stellen van open vragen de patiënt ertoe brengt opening 
van zaken te geven. Dit blijkt lang niet altijd het geval. Er zijn patiënten die naar aanleiding van open vragen heel weinig informatie geven. Er zijn echter ook patiënten die zo veel informatie verstrekken dat het moeilijk wordt uit te maken wat relevant is en wat niet. Voor studenten is het dan moeilijk om de structuur van het gesprek te bewaken. Als reactie gaan studenten vaak gesloten, medisch-technische vragen stellen. Het gevaar bestaat daarbij dat aan de werkelijke beweegredenen van de patiënt om het spreekuur te bezoeken wordt voorbijgegaan.

De twee bovenbeschreven problemen - weinig informatieve vraagverheldering en, als reactie daarop, premature medischtechnische ondervraging - worden in het nieuwe curriculum aangepakt door de vraagverheldering op te rekken tot een verkenning van het referentiekader van de patiënt en deze apart in te trainen. Als leidraad voor deze verkenning van het referentiekader van de patiënt is het biopsychosociale ziektemodel gekozen, waarin de belangrijkste contextvariabelen van de klacht in kaart gebracht kunnen worden. ${ }^{1-4}$ Dit model is in figuur 1 schematisch weergegeven.

\section{Het Biopsychosociale ziektemodel}

Studenten krijgen met dit ziektemodel (figuur 1) een kapstok aangeboden om systematisch te werk te gaan en de drie dimensies van het model zorgvuldig en klachtgericht uit te vragen.

In de praktijk gebruiken de studenten als ezelsbruggetje de letters van het niet bestaande woord SCEGS. In de biologische dimensie leert de student te vragen waarom de patiënt op het spreekuur is gekomen en daarbij de patiënt aan te moedigen zijn symptomen en klachten te vertellen, zoals hij deze zelf ervaart. Het gaat daarbij eerst alléén om die symptomen die de patiënt zelf van belang acht. In
Figuur 1. Het biopsychosociale ziektemodel.

\section{Het Biopsychosociale Ziektemodel}

S Biologische dimensie:

Klachten zoals de patiënt die ervaart

\section{Psychologische dimensie:}

C - cognities: wat weet, denkt, fantaseert de patiënt over de klacht en waarom? wat zijn zijn verwachtingen van het consult (en/of arts)

E - emoties rond de klachten, b.v. angst voor bepaalde ziekte, ongerustheid, somberheid etc.

G - gedrag op geleide van de klacht, wat doet/laat de patiënt vanwege de klacht

S Sociale dimensie:

Wat voor gevolgen heeft de klacht voor de sociale relaties, b.v. hoe uit hij de klacht naar zijn omgeving, gezin, collega's, vrienden en ook: hoe reageert de omgeving daarop naar patiënt. Hoe intervenieert de klacht in het sociale leven van de patiënt?

Aangevuld met de vraag: Waarom komt deze patiënt op dit moment met deze klacht bij mij?

\section{Gebruikte vaardigheid: Vooral Volgen!}

deze fase dient de student zich te beperken tot "actief luisteren". Het is niet de bedoeling rijtjes gerichte en gesloten vragen te stellen. Het toetsen van een eigen hypothese moet wachten tot een latere fase (speciële anamnese). Parafraseren en interventies als, "o ja, vertel nog eens verder" of "dat is me nog niet helemaal duidelijk" en "kunt u er nog eens wat meer over vertellen” zijn wel toegestaan.

Vervolgens komt de psychologische dimensie aan bod, waarin drie onderdelen kunnen worden onderscheiden: cognities, emoties en gedrag. De cognities omvatten alles wat de patiënt over zijn klacht denkt, 
weet, fantaseert en ook wat zijn verwachtingen zijn van de dokter en het consult. De emoties zijn ook klachtgebonden. Is er bijvoorbeeld sprake van ongerustheid over de klachten, voelt de patiënt zich misschien somber vanwege zijn symptomen, et cetera. Daarna worden vragen gesteld over het gedrag. Wat doet of vermijdt de patiënt omdat hij deze klachten heeft. Tot slot wordt nog de sociale context van de patiënt verkend. Hoe uit de patiënt de klacht naar zijn omgeving, welke nieuwe attributies draagt de omgeving aan, et cetera.

Het blijkt dat studenten met behulp van dit model empathische interventies beter kunnen combineren met gerichte vragen. Door de klacht als leidraad te nemen voor vragen naar deze contextgegevens, voelen studenten zich meer gelegitimeerd om naar allerlei zaken uit het privé-domein van de patiënt te vragen zonder dat zij daarbij het gevoel krijgen de grens van het gepaste te overschrijden.

Dit model biedt de volgende voordelen:

- Het biedt structuur.

- Het voorkomt stuurloosheid en studenten voelen zich daardoor minder onzeker.

- Open en gesloten vragen wisselen elkaar op natuurlijke wijze af.

- De patiënt komt tot zijn/haar recht.

- De patiënt ervaart deze actieve verkenning als belangstelling, betrokkenheid.

- De op deze wijze verzamelde informatie is relevant voor: het diagnostisch proces en voor beleid en/of therapie.

Een bijkomend voordeel is dat het model structuur en uniformiteit biedt aan observatoren en docenten.

\section{Uitvoering}

Alle onderdelen van dit programma, dus zowel de vraagverheldering als de speciële en tractusanamnese worden gestructureerd aangeboden. Na een uitleg voor de hele groep studenten volgen enkele gerich- te zelfstudieopdrachten. Vervolgens wordt in een werkgroepbijeenkomst in carrouselvorm door de studenten onderling geoefend. Deze werkgroep wordt begeleid door een docent medische psychologie en een tutor (een arts). Tot slot volgen oefeningen met simulatiepatiënten in kleine groepjes van drie studenten waarbij elke student meerdere malen oefent en persoonlijk feedback krijgt van de betreffende patiënt.5, 6 Daarnaast observeert de student ook de consulten van twee medestudenten. Deze sessies worden afwisselend door medisch psychologen en tutoren begeleid. Steeds wanneer een onderdeel van de anamnese wordt toegevoegd, wordt tevens de integratie met de eerder geleerde onderdelen geoefend.

Aan het eind van het blok heeft elke student vijfmaal een gesprek met een simulatiepatiënt gevoerd en hier feedback op ontvangen (tweemaal vraagverheldering, tweemaal vraagverheldering geïntegreerd met speciële anamnese, en eenmaal een volledige anamnese) en tienmaal een consult van collega's geobserveerd.

\section{Evaluatie}

Studenten blijken de fase van vraagverheldering aan de hand van het SCEGSmodel over het algemeen als zinvol te ervaren, omdat zij er houvast aan hebben. Docenten die bedside teaching geven en van dit onderwijs onkundig zijn, rapporteren spontaan dat ze, anders dan voorheen, studenten zien die, met dit model, een echt gesprek met patiënten weten te voeren. Ook melden sommige docenten dat zij, als ze dit model zelf hanteren, soms compleet nieuwe informatie krijgen van patiënten die zij zelf al jaren kennen.

De gangbare evaluatie bestaat uit een aantal vragen die gescoord kunnen worden op een vijfpuntsschaal. In het kader van de beschrijving van deze training zijn 
Tabel 1. Gegevens van de evaluatie door de eerste acht groepen studenten die deelgenomen hebben aan het programma communicatietraining in het derde studiejaar in 1997/98 ( $n=173)$ en 1998/99 ( $n=160)$.

\begin{tabular}{lccccccccccc}
\hline & \multicolumn{1}{c}{ groepen in $1997 / 98$} & \multicolumn{7}{c}{ groepen in 1998/99 } & Totaal \\
& $\mathbf{1}$ & $\mathbf{2}$ & $\mathbf{3}$ & $\mathbf{4}$ & $\mathbf{1}$ & $\mathbf{2}$ & $\mathbf{3}$ & $\mathbf{4}$ & \\
\hline Wat vindt u van de inhoud van het onderwijs* & 4.7 & 4.7 & 4.7 & 4.8 & 4.8 & 4.8 & 4.7 & 4.7 & 4.7 \\
Wat vindt u van de vorm van het onderwijs** & 4.4 & 4.4 & 4.5 & 4.5 & 4.4 & 4.3 & 4.3 & 4.5 & 4.4 \\
\hline
\end{tabular}

* vijfpuntsschaal: 1=zeer irrelevant; 5=zeer relevant

** vijfpuntsschaal: $1=$ zeer slecht; $5=$ zeer goed

twee vragen relevant (tabel 1). In de acht groepen die tot nu toe dit onderwijs gevolgd hebben, wordt zowel inhoud als vorm zeer hoog gewaardeerd.

De vraag naar de inhoud van het onderdeel communicatietraining, die kon worden gescoord van "zeer irrelevant" tot "zeer relevant”, werd door de twee jaargroepen die het programma inmiddels hebben doorlopen, beoordeeld met een gemiddelde van 4.8. De tweede vraag over de vorm van het onderwijs, te scoren tussen "zeer slecht" en "zeer goed", werd met een gemiddelde van 4.4 beoordeeld.

Voorts konden de studenten op de evaluatieformulieren aangeven wat zij het meest leerzame onderdeel van dit blok vonden. Door de studenten van jaargang 1997/1998 werd op zestien van de 180 evaluatieformulieren op deze plaats iets ingevuld. In dertien van deze zestien gevallen werd communicatietraining en/of de oefeningen met de simulatiepatiënten als het meest leerzame onderdeel genoemd. Dit was ook het geval in 56 van de 71 reacties op de evaluatieformulieren van jaargang 1998/1999.

Deze resultaten moedigen ons aan om op de ingeslagen weg verder te gaan en het onderwijs in communicatietraining op dezelfde manier verder uit te bouwen. Het streven daarbij is om, voordat het artsexamen wordt afgelegd, in de lijn van dit model en conform bovenbeschreven didactische methode, allerlei vormen van medische consulten te demonstreren en te trainen.

\section{Literatuur}

1. Engel GL. The biopsychosocial model and the education of health professionals. Ann NY Acad Sci 1978;310:169-81.

2. Spaendonck KPM van, Lisdonk EH van de. Het biopsychosociale ziektemodel: een proeve van onderwijskundige operationalisatie. In: Pols J, Cate ThJ ten, Houtkoop E. Pollemans MC, Smal JA, redactie. Gezond Onderwijs-4. Houten: Bohn Stafleu Van Loghum; 1995. p. 272-6.

3. Spaendonck KPM van, Bleijenberg G, Wollersheim H, Keijser K. Cursus interactieve consultvoering voor arts-assistenten. In: Verweij AMJJ, Albersnagel EA, Cate ThJ ten, Denekens J, Dikkers JH, Remmen R, Smal JA, Spaai GWG, redactie. Gezond Onderwijs-7. Houten/Diegem: Bohn Stafleu Van Loghum; 1998. p. 287-98.

4. Dulmen AM van, Fennis FJM, Mokkink HGA, Velden HGM van der, Bleijenberg G. Doctor-dependent changes in complaint-related cognitions and anxiey during medical consultations in functional complaints. Psychol Med 1995;25:1011-8.

5. Weel-Baumgarten EM van, Spaendonck KPM van. Feedback door simulatiepatiënten ook op inhoud, kan dat wel? In: Smal JA, Cate ThJ ten, Denekens J, Dikkers JH, Remmen R, Smal JA, Spaai GWG, Verweij AMJJ, redactie. Gezond Onderwijs-6. Houten/Diegem: Bohn Stafleu Van Loghum; 1997. p. 268-72.

6. Spaendonck KPM van, Weel-Baumgarten EM van. Feedback. In: Metz JCM, Scherpbier AJJA, Houtkoop E, redactie. Gezond Onderwijs-2. Nijmegen: Universitair Publikatiebureau Katholieke Universiteit Nijmegen; 1993. p. 62-5. 
De Auteurs

E.M. van Wel-Baumgarten is huisats en coordinator van het onderwijs met simulatepatienten, Klinisch Traingscentwm, Katholike Universiteit Nimegen. K.PM. wan Spaendonck is medisch psycholoog en onderwijsoöninator medische psychologie, Thkgep Medische Psychologie, Katholieke Universiteit Mimegen
Correspondentieadres:

E.M. van Wel-Bawganen, Klinisch

Thainingcentum, 108 ALCO, Postbus $9101,6500 \mathrm{HB}$ Nimegen, tel: $024-3616330 / 9616786$,

fax: 024-3560430, e-mailadres: evanwelonss.fmw.n. 